\title{
Automated Vehicles and Automated Driving from a Demand Modeling Perspective
}

\author{
Rita Cyganski
}

\subsection{Motivation and Aims}

In 2013 Willumsen, one of the most renowned researchers in transport modeling, stated, regarding automated vehicles: "We can no longer ignore them, if [the] planning horizon is $10+$ years" [37]. But works attempting to anticipate the effects of automated vehicles on potential users' everyday mobility, and specifically their choice of transport mode, are still rare (e.g. [11, 19, 37]). However, a glance at the individual driving forces of our daily mobility behavior does allow us to draw some cautious conclusions on potential behavioral changes arising from the introduction of automated vehicles. Applying analogies to the use of known transport modes in transport demand modeling allows for initial quantitative statements about potential impacts on overall transport demand. In the process, demand modeling allows us to distinguish between different geographic contexts and user groups, and to evaluate various scenarios for the use of such systems.

The aim of this chapter is to sketch out challenges and initial approaches on how to incorporate automated vehicles among the choices of transport mode when modeling demand in passenger transport. First, we will examine which factors play a central role in the individual processes when weighing up the various transport modes. The following section gives a short introduction into transport demand modeling's manner of operation. We shall then turn our attention to what behavioral changes may appear in transport modal choice as a result of introducing automated vehicles. We will discuss what properties of the new vehicles, and also of the geographic context and potential users themselves, could be significant in how the vehicles are perceived and received, and what competitive situation between transport modes this will result in. To support this work, we shall

\section{R. Cyganski ( $\square)$}

German Aerospace Centre (DLR), Institute of Transport Research,

12489 Berlin, Germany

e-mail: Rita.Cyganski@dlr.de 
introduce the initial results of an online questionnaire on attitudes to automated vehicles and their anticipated use. The concluding section addresses the following questions: What are the challenges when integrating automated vehicles into model-supported transport demand analysis? How do current models and data bases need to be expanded to give an adequate mapping?

\subsection{What Determines Which Transport Mode We Choose?}

The question as to why we decide in favor of a certain mode of transport occupies a multitude of publications from various disciplines. There is consensus that a vast number of complex interdependent factors underlie human transport behavior and mode choice. According to Bühler (2001), these subdivide into four groups: (1) socio-economic and demographic characteristics, (2) cultural frameworks and individual preferences, (3) spatial development patterns and (4) political regulation [6]. Alongside personal criteria, Ortùzar and Willumsen [24] see the characteristics of the intended journey and, not least, of the transport supply and of the modes available as being most decisive.

Of special significance in mode choice is the question of access to alternative modes of transport. Driver's license ownership, individual income situation and closely related car ownership are important behavioral determinants. Substantial investments such as purchasing a car or a season ticket for public transportation have a long-term impact on transport mode choice [31]. Clear differences in modal choice can be seen in terms of sex, employment status, and household size and structure. Further, the presence of children in a household has a particular influence $[6,24,28]$. But it is not only objectively measurable criteria that play a role. Individual personal circumstances, lifestyles, and attitudes towards the various transport modes and traveling itself affect the decision, as do daily habits and routines (see [25, 27, 29, 33]). The effect of transport socialization and social and environmental norms is stressed in the approaches of learning theory and cognitive and social psychology (see $[2,12,27])$. These show clearly that individual decisions often do not correspond to the idealized picture of an independently and rationally deciding human being.

Residential location is considered to be the main spatial anchoring point for individual transport related decisions. Its physical structures directly affect the accessibility of destinations looked at visiting and the effort it takes to get to them ([6, 9, 27], Chap. 20). For instance, higher population density, greater mix of uses, and proximity of public transportation are associated with lifestyles with lower car use and higher rates of walking and cycling. At the same time, traffic jams, shortage of parking space, and higher parking costs are more common in densely populated areas [6].

If nothing else, the financial cost of using a transport mode is a direct or indirect consequence of political regulation. Operating costs, road tolls, and parking costs influence how people view their cars. Travel time, particularly in comparison to the time needed for the alternative transport modes available, is another important selection criterion. In this context, it should be distinguished between time spent on pre- and 
post-usage, e.g. the way to and from bus stops, and time actually spent travelling on the bus. In the case of public transport, moreover, it can be shown that waiting and transfer times, and the number of transfers, have a considerable impact on how the mode is evaluated Wardman [36]. However, it is not only instrumental factors that play a significant role, but also the associated symbolic and affective ones [33]. For instance, a transport mode's alleged or actual reliability and punctuality affect the decision for or against a specific transport mode, as do its associated safety, convenience, pleasure, and flexibility [4, 24, 33].

Selecting a transport mode, furthermore, also depends on the purpose of the journey. Here, not only the individual trip but the whole trip chain, i.e. all journeys undertaken between leaving the home and returning to it, should be considered [4]. The number and type of accompanying persons can also be decisive in selecting a means of transport, as can transportation needs or the distance to be covered [16, 25, 33].

\subsection{Transport Mode Choice in Applied Transport Models}

\subsubsection{A Short Introduction to Transport Demand Modeling}

Transport demand models are important and established tools in transport-related planning and decision-making processes. They allow for analysis of the present transport situation, forecasting of future developments in transport demand, or the examination of various potential development paths based on scenarios. The basis of a transport demand model is the simplified, purpose-specific representation of interdependencies between mobility demand and its concrete geographic manifestation. Transport models are mathematical models that place high demands on the extent and depth of detail of the input data, and which, particularly in relation to human decision-making processes and present transport demand, rely on extensive empirical data.

The aim of passenger transport modeling is to represent all decisions of individuals made as a consequence of a planned change of location. The first model stage, trip generation, addresses the question of how many changes of location are made in the study area. To this end, the number of trips or activities that can be expected for the population according to statistics within one day is determined. In the process, the generated trips or trip chains are differentiated according to trip purpose. In the next step-destination choice or trip distribution - a destination is selected for each trip depending on its purpose. Given the combination of origin and destination, the third model step-transport mode choice or transport allocation - weighs up the various available transport modes and selects one of them. The next step - traffic assignment or route choice-determines the route taken from origin to destination and sometimes specifies the starting time in more detail. The basis here is the so-called supply model, in which the transport system for all available transport modes is mapped in such detail that the attributes for each potential route - such as travel times between two locations - can be determined. As a 
result, a transport demand model provides information on the location changes of the study area's population and the resultant traffic volumes for individual modes of transport. In practice, the individual stages of the model, presented here for the sake of simplicity as a sequential process, often find simultaneous or recursive application-choice of transport mode and destination are combined particularly often. For a more in-depth look at transport demand modeling, see [5, 24].

As a rule, transport demand models can be divided into microscopic and macroscopic model approaches. These approaches differ both in view of the information and properties required and the model logic in mapping decision interrelationships. Macroscopic demand models, also often called Four-Step Models or FSM, directly reflect the four stages mentioned above. Based on its socio-demographic, transport-related characteristics, the population in the study area is subdivided into groups so that behavior within a group is as similar as possible while deviating significantly in comparison to the other groups. Classifications are typically based on sex, age, employment status, and car ownership. Usually, household context is not considered (for more details, see [18], inter alia). In the course of modeling, all trips generated by group members are modeled collectively and independently from other changes of location during the day in question. For further description of macroscopic models, see [5, 22].

Particularly in regional modeling in the USA, so-called activity-based or microscopic modeling approaches to transport demand have grown in significance in recent years. Compared to macroscopic models, these are more greatly focused on people's individual mobility decisions and consider a person's detailed characteristics and household context to a greater extent. A day's individual trips are modeled jointly as tours starting and ending at home. This form of representation allows for consideration of behavioral interdependencies between individual activities and decisions. In the course of microsimulation, the trip chains of all persons in the study area are calculated individually, yielding an overall picture of transport demand. In-depth information on activity-based modeling approaches can be found in [7, 10, 21].

\subsubsection{Decision-Making Criteria in Applied Models of Transport Mode Choice}

Transport mode choice is of great significance in demand modeling, with its results being highly relevant for planning and policy [24]. Generally, discrete choice models or closely related methods that presuppose strongly rational decision-making behavior are employed. These statistical models help to identify the respective influencing factors and the extent of their impact on decision-making. If one assumes that the total utility of a choice alternative can be derived additively from the individual components, then benefit of choosing an option can be calculated and compared with other available alternatives. The probability of selecting one variant increases with its relative advantages compared to other options [20, 24]. The specified models can differ in their complexity (see [34], 
for example). Transport mode choice models that are integrated into demand models, however, usually only consider a few variables covering the characteristics of the transport mode, the people, the trips, and the geographic structure.

In describing the available transport modes, the financial and temporal costs of a choice assume prime importance. In the case of cars it is primarily running costs that are considered, purchase and maintenance costs more rarely. Time costs are primarily taken to be average onboard travel times. Less frequently, and then mainly for public transport, is time spent getting to and from the bus or train included. In the latter case, the number of transfers, waiting and transfer times, or even service frequencies are often also taken into consideration. Elements such as the reliability of the travel time have until now mainly been found in analytical models [4]. By using a transport mode specific constant, moreover, utility components that cannot be further specified may be considered in aggregate. Age, sex, income statues, driver's license and car possession are among the typical socio-demographic attributes in the models. Income variables, level of education, and household size or number of children are rarer. In particular for socio-demographic characteristics, it is common to interrelate with other attributes when determining their utility components, thus allowing different levels of influence for specific groups of people. Assessing transport modes may also depend on the trip purpose; interaction terms specific to the trip purpose are thus also not uncommon. Distinguishing journeys to work is particularly important here. But also the need to transport items, or commonly having accompanying passengers for specific trip purposes, such as shopping or longer travelling, may require corresponding differentiation. Geographic and contextual characteristics form a further area. Official geographic typification, or population density at the residential location, e.g., can be used to differentiate between rural and densely populated areas. Factors describing the parking situation, parking costs or possible toll areas can also be found in some models.

Transport demand models are strongly data-driven and presuppose that quantitative statements on interdependencies can be made. In the absence of sufficient data, numerous factors known to be relevant for transport mode choice can often only be included in models in simplified form. This particularly affects so-called "soft factors" such as routines, transport modes' perceived comfort and reliability, the pleasure associated with traveling by such means, the social standing conveyed, individual safety requirements, and propensity for privacy. It is not only attitudinal factors, however, that are examples of issues that, despite their known relevance, have hitherto hardly been considered in transport demand modeling, but also knowledge of alternatives, the potential effort needed to plan, and also the way in which households come to collective decisions (see [35], among others).

Mapping new transport modes poses a particular challenge, moreover. The liberalization of long-distance bus services in Germany, the introduction of station-based carsharing services, or even the introduction of electric cars onto the market are examples of modifications of existing transport provisions where forecasting usage patterns has proved to be difficult and reliable figures on interdependencies are lacking. But even differentiating 
between the various current modes using "hard" factors is not always easy. Transport models have historically mainly been employed to calculate the vehicle miles travelled. As recently as 2012, Bates showed that four-stage models contained barely more than one distinction between "private modes," i.e. car usage, and "public modes". These have only recently been extended to include other aspects, such as distinctions between driver and passenger [5]. Distinguishing among cars, for example according to size or type of drive, has only latterly been introduced in modeling. This all amounts to a series of significant challenges when integrating automated vehicles into the analysis. Ultimately, it is a matter of examining "the car" more closely and enabling clear differentiation between driving and being driven, a car you own and a car you hire, or a taxi, even.

\subsection{What Impact Might the Roll Out of Automated Vehicles Have on Our Behavior in Choosing Transport Modes?}

Before examining the question of how automated vehicles can be looked at in transport modeling, it must be explained how the introduction of these systems might affect individual daily mobility. In general, the potential use of automated vehicles, or also of new mobility options, greatly depends on their possible applications and the advantages they offer compared to other modes on offer - that is to say, on factors relevant to how automated vehicles are judged compared to other modes when choosing transport modes. Such factors should then, as far as possible, be included in models. For the use cases described mostly in technical or legal terms in Chap. 2, I will therefore begin with a discussion of possible usage variants. Central issues requiring further examination here include: how to typify the expected users, the trip purposes and intended uses for which corresponding systems are particularly suited, the geographic or contextual characteristics that make it necessary to use public transport, the relevant transport mode characteristics and the transport mode substitution that may result from this. The discussion is hereby focused on characteristics suitable for depiction in transport models.

\subsubsection{Interstate Pilot: The Car with that Special Something for Exceptional Circumstances?}

Interstate Pilot may come to be the entry level for automation, as the driving task remains except in exceptional circumstances. The two main aspects of Interstate Pilot from a user perspective are easing the driver's workload and the possibility of spending travelling time in other ways.

The use of Interstate Pilot will only be possible on specific stretches of road, and thus mainly on long-distance trips. For this reason, it may be assumed that this system would mainly positively impact how cars are perceived and assessed in the case of longer journeys. In addition, Continental's user survey clearly shows that handing over the driving task is positively connoted, especially in stressful or tiresome situations such as 
traffic jams or roadworks [8]. It is also not uncommon, however, to associate such a handover with restricting the pleasure of driving [1].

After increased road safety, the possibility of an altered use of time, mostly associated with increased meaningfulness or productivity, is arguably the most-mentioned advantage of automated vehicles (see [23, 26, 30, 32], for example). For working people and those with great private commitments in particular, and for trips with children or with other passengers, this could lead to time spent travelling being viewed more positively — one of the most important factors for transport mode choice in models. In the end, this may lead to longer trips on public transportation being assessed relatively more negatively, particularly by people who use this time actively, and to cars being perceived as the more-comfortable alternative, leading to them gaining in popularity. The significance of the alternative time usage is, however, difficult to assess. In the Continental study, for example, only around a third of respondents stated that they found an alternative time use attractive [8].

\subsubsection{Valet Parking-Never Look for a Parking Space Again?}

Valet Parking is a function in more or less "normal," only slightly modified cars, where the driving task remains unchanged. The vehicle only takes over the task of parking and driving to pick its occupants up autonomously within a defined radius upon user request. According to a survey by AutoScout24, just under two thirds of respondents would happily use this function and never again search for a parking space themselves. Among residents of urban districts, this percentage is higher, as would be expected [1]: The function is mainly of benefit in areas with a low number of private parking spaces, where there is pressure on parking, and long distances from homes or destinations to their respective parking spaces (see also Chap. 20). It thus helps to save time and also parking costs, where applicable [19], and it provides greater convenience, particularly when transporting items or children, and for people with restricted personal mobility. Even if greater use of carsharing is discussed primarily in the case of Vehicle on Demand (see [11]), less time and effort spent getting to the car with Valet Parking may possibly ease the use of carsharing. Consequences that we can be surer of include a substantial drop in parking search traffic, and an accompanying fall in travel times in areas previously affected by this.

\subsubsection{Arriving Comfortably and Safely in a Fully Automated Vehicle}

Fully automated driving is the "crème de la crème of driver-assistance systems" [3]. Although the human driver will — at least provisionally — need to be in a position to take over the driving task, this should only be necessary when desired. Given sufficient rates of penetration, this driving concept is linked with a vision of safe, reliable personal mobility 
and improved traffic flow leading to less time spent travelling and in jams, as well as making the planning of journey times and costs more predictable $[3,26,30]$. At the same time, it may be assumed that inhibitions regarding car usage and ownership will decrease, especially for users who are inexperienced, uncertain or older. The car would thus become, for instance, a more attractive option in unfavorable driving conditions such as darkness, unknown or longer routes, and in bad weather conditions (see also [11]). One consequence of this is a possible fall in the number of escorting trips and the use of taxis and public transport, and a corresponding increase in car ownership.

The most frequently cited advantage from users' point of view, however, is the associated hope — analogous to Interstate Pilot — of being "given time that I can use solely for me" [26]. It is therefore no surprise that this technology's target group is mostly seen as being working commuters (see [17] for example) - fully automated driving provides, precisely in urban densely populated areas, meaningful use of time spent on-board. This benefit is likely to result in a more positive evaluation of the car, especially if time spent in cars was not previously perceived as productive, and pleasure in driving not a priority. We thus see it is particularly people who are not the most passionate drivers who most desire to use such a function [17].

\subsubsection{Vehicle on Demand_Zipcar on Steroids?}

A scenario involving a fleet of vehicles that is in large part available and usable for everyone, particularly in urban areas, would undoubtedly have the most wide-ranging impact on daily transport behavior. A logical extension of fully automated vehicles, but with no option of taking over the driving function, it would allow for independent personal mobility even for those without a driver's license or their own car: children, the elderly, people who are sensory or mobility impaired, etc. (see [19], among others).

In general, we can assume that cars will gain in attractiveness as access and egress times decreases, especially in areas with a parking-space shortage. Alongside the potential drop in parking costs from being able to park further away from the destination, a clear fall in the number of escorting trips may also be expected, as well as in the use of carpooling and taxi services-possibly accompanied by an increase in empty runs.

At the same time, introducing Vehicle on Demand fleets is universally expected to lead to substantially lower rates of car ownership [19], [37], possibly accompanied by a boom in carsharing use. With reference to the US carsharing firm, Silberg et al. [30] have even spoken of "Zipcar on steroids". It seems particularly plausible that two-car households might substitute their second vehicle, which-depending on the situation in terms of weather, parking availability, number of people travelling, etc.- - would also allow a specific vehicle to be selected accordingly (see [17, 37]).

Given Vehicle on Demand's introduction, Fagnant and Kockelman [11] would expect a substantial impact on individual car ownership. According to their simulation calculations for the USA, a single Vehicle on Demand could replace up to 13 private cars [11]. 
Studies on station-based carsharing in Germany put the substitution rates at up to eight private cars replaced by a single carsharing vehicle [15]. Because Vehicles on Demand can cover a wider catchment area by abolishing the need for trips from the starting point to the vehicle, these figures do not appear unrealistic. A glance at carsharing's current user structure provides the first clues as to the potential users of Vehicle on Demand. In particular, younger people of higher-than-average education and income with distinct interest in the environment use station-based carsharing in Germany. The fairly new carsharing services that are not tied to stations, also known as flexible carsharing, are mainly used by urban males as a flexible transport mode option for short trips (see [13, 14]). The use of Vehicle on Demand as an alternative to privately-owned cars might thus directly lead to a boost in multimodal behavior in choosing transport modes, or contribute to an increase in carpooling (see [26]). However, given that time spent in the vehicle is often viewed positively, a rise in car use and mileage covered is also possible as a consequence of their omnipresent availability ([11, 37], Chap. 20). These new mobility concepts are examined in depth in Ch. 18.

But it is not only individual car ownership that may be subject to extensive changes in such a scenario. Car services, taxis and public transport may find that competition with personal transport modes hots up anew. Especially in rural areas, Vehicle-on-Demand fleets could serve either as flexible, individual feeder services for local public transport, or as a way of comfortably covering the "last mile" for long-distance public services. Critical analyses, however, also allow for the theory that they would not simply supplement public mass transit, but in the long run could even replace it: "[...], eventually, mobility on demand may prove a better investment than new mass transit systems" [17], an assessment also shared by Willumsen [37]. In this case, assumptions that passenger kilometers covered on an individual basis may rise steeply surely cannot be rejected out-of-hand.

\subsubsection{The Car of the Future: Competition for Cars, Taxis or Trains?}

Reviewing the literature as it stands shows that introducing automated vehicles could have very diverse effects on our daily mobility and chosen means of transport. Automated driving thus is not always only a lightly modified version of our long-familiar cars that will improve traffic flow and travel times and provide support functions as desired, as suggested by a graphic in the KMPG study [17]. Rather, its potential effects differ enormously for existing private transport modes, and even public ones. The wide-ranging implications resulting from the various scenarios for the whole transport system and the use of public space generally are explored in depth in Chap. 20. The possible effects on transport mode choice, as seen in the literature above, clearly show that the characteristics relevant for perception and valuation of the vehicles in the various usage scenarios may be very different. These diverse requirements must be borne in mind when analyzing any potential mapping of automated vehicles in transport demand modeling. 


\subsection{What Potential Applications Do Users Anticipate for Automated Vehicles? Initial Survey Findings}

Quantitative studies on the topic of automated driving have been carried out sporadically since 2012 [1, 8, 17]. The surveys have largely focused on issues of attitudes and acceptance, or on desired support functions. With its questions on anticipated usage and alternative time use, Continental's mobility study from 2013 [8] is noteworthy in this connection. However, all of the studies have in common that they do not consider any differentiation in the possible forms of automated driving, and are not targeted at possible behavioral changes or potential intended applications.

For this reason, a survey was carried in June 2014 which provides the basis for the empirical findings of both this article and those on the form of the human-machine interface (Chap. 26) and the acceptance of automated vehicles (Chap. 28). This quasi-representative online survey addresses respondents' attitudes and their anticipation of how they would use automated vehicles in the project's various use cases. The sample comprises of 250 complete questionnaires per usage scenario (total 1000) and is stratified according to sex, age, income and education. Using quantitative methods, the dataset allows for an initial evaluation of various user groups' attitudes to automated driving and mobility provision. This supplements the previous section's findings. From a demand modeling perspective, the survey's aim is mainly to comprehend what differentiations with respect to users, trip purposes, intended applications, and transport mode characteristics are relevant when modeling automated vehicles. Also, data analysis should provide the first indications of which transport modes, from today's perspective, automated vehicles would compete with for users, and of how time spent traveling may change, and how these changes are viewed.

The questionnaire begins with questions covering the respondents' socio-demographics, their knowledge of and interest in automated driving, and their previous experience of assistance systems. This is followed by questions on their current use of, and attitudes to, existing transport modes and the usual way they spend time when using them. The respondents also answer in-depth questions on one of the project use cases-Interstate Pilot, Automated Valet Parking, Full Automation and Vehicle on Demand (see Chap. 2). Topics include anticipated use, the transport mode that would be replaced, attitudes towards the vehicle described, the need to be able to intervene, various aspects of the experience, and specific design wishes. The scenarios are described fairly briefly to leave room for the respondents' own interpretations. A tabular overview of the participants' socio-demographic characteristics and the sample structure can be found in Chap. 26. 


\section{I can imagine replacing my previously preferred transport mode with} such a vehicle.

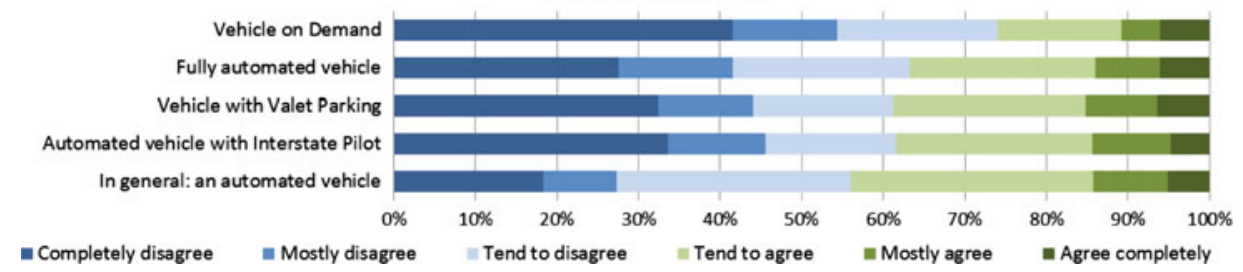

Fig. 12.1 Stated willingness to substitute favored transport mode with an automated vehicle generally and in the various use cases. Image rights: copyright by the Author

\subsubsection{Who Can Imagine Substituting Their Previously Preferred Transport Mode?}

To evaluate automated driving's impact on transport mode choice, it is especially important to know what transport modes automated vehicles may replace. To this end, in one of its first questions, the survey enquires into participants' basic willingness to substitute their preferred transport mode with an automated vehicle — at this stage an undifferentiated one. As the questionnaire continues, the respondents are also asked, for one of the use cases, if they could imagine using the vehicle specified or substituting their preferred transport mode with it. The results were also examined as to whether significant differences could be seen in answers according to respondents' socio-demographic characteristics and attitudes. ${ }^{1}$ Corresponding relevant statistical values can be se seen as indicators that, when integrating behavior into the models, it should be differentiated according to these criteria - the specific strengths or tendency of the effect is of secondary importance at first.

Figure 12.1 gives the respective answers on substitution desires, which tend to correspond to the general willingness to use automated vehicles (see Chap. 27). It is striking that the majority of respondents can either hardly imagine, or cannot imagine at all, giving an automated vehicle preference over their standard transport mode. Fewer than $15 \%$ of respondents agree with the statement of wanting to use an automated vehicle- no matter what kind - predominantly or as a full replacement. While the proportion of undecideds is very high for the general statement, the agreement value falls sharply for the specific scenarios, between which there is statistically significant variation. With only around a quarter of positive answers, the Vehicle on Demand use case stands out here as being regarded with especial skepticism. Full Automation, on the other hand, is viewed most positively on average.

\footnotetext{
${ }^{1}$ In the following, differences are indicated as statistically significant when exhibiting values of 0.05 or lower in a Pearson's chi-squared test. For some variables, particularly attitudinal or geographic ones, a test was not always possible, due to the number of cases in individual answer categories.
} 
A differentiated analysis of the desire to switch modes can reveal statistically highly significant differences in terms of household size, presence of children, income, and the number of cars in a household. The most clearly discriminatory factor, however, is attitudes towards cars. These are revealed in questions on what people associate with car driving and whether they take pleasure in it, and also whether respondents could set up their daily lives without a car. Residential location also produces clear differences in the answers. Rural dwellers, for example, are less skeptical in their answers than people in cities. Sex, levels of education and income, in contrast, do not have a statistically significant impact on the answers given, nor does shortage of parking at home or other main reference locations. Looking at the individual usage scenarios, it is notable that there is higher skepticism towards Vehicle on Demand among women, as well as marked differences in the answer patterns vis-à-vis Valet Parking, depending on the presence of children, household size, and income.

The participants were also asked how, in their opinion, using an automated vehicle from one of the scenarios would affect their previous transport mode use. The answers were given separately for each previous transport mode and ranged from "far less often" $(-2)$ to "far more often" $(+2)$. The large percentage of those who assume no change in their behavior is also conspicuous here: With the exception of taxis and conventional cars, a number of respondents consistently between 50 and $64 \%$ state they foresee no change in their transport mode use. The respective mean values of answers given for individually anticipated mode shift effects are shown in Table 12.1. A mean value of 0 is to be taken as indifference. Taxi use is estimated to fall in all scenarios. It is noticeable that Valet Parking produces the greatest associations of switching - particularly from taxi use, with its very low mean value of -0.78 .

Table 12.1 Effects of scenarios on previous transport mode use

\begin{tabular}{|l|l|l|l|l|l|}
\hline Scenario & $\begin{array}{l}\text { I would take a } \\
\text { public transport } \\
\text { mode } \ldots\end{array}$ & $\begin{array}{l}\text { I would } \\
\text { cycle or } \\
\text { walk } \ldots\end{array}$ & $\begin{array}{l}\text { I would } \\
\text { take the } \\
\text { train } \ldots\end{array}$ & $\begin{array}{l}\text { I would } \\
\text { take a } \\
\text { taxi } \ldots\end{array}$ & $\begin{array}{l}\text { I would drive in } \\
\text { a conventional } \\
\text { car ... }\end{array}$ \\
\hline $\begin{array}{l}\text { Interstate } \\
\text { pilot }\end{array}$ & -0.36 & -0.28 & -0.35 & -0.70 & 0.04 \\
\hline $\begin{array}{l}\text { Valet } \\
\text { parking }\end{array}$ & -0.44 & -0.28 & -0.51 & -0.78 & -0.32 \\
\hline $\begin{array}{l}\text { Full } \\
\text { automation }\end{array}$ & -0.33 & -0.11 & -0.41 & -0.74 & -0.23 \\
\hline $\begin{array}{l}\text { Vehicle on } \\
\text { demand }\end{array}$ & -0.33 & -0.15 & -0.35 & -0.78 & -0.13 \\
\hline
\end{tabular}

Mean values of answer options -2 far less often; -1 less often; 0 just as often; 1 more often; 2 far more often 


\subsubsection{What Do Respondents See as the Specific Advantage of Automated Vehicles?}

A further question asks for which intended applications and trip characteristics the respondents would find automated vehicles to be particularly helpful. The answers' mean values are given in Table 12.2. With the exception of escorting trips, there are consistently highly significant differences between the scenarios. This indicates that the respondents may clearly differentiate between the scenarios. The comparatively high agreement values for Full Automation for long-distance trips and excursions are noteworthy, to a lesser extent for trips with higher occupancy rates. Valet Parking is viewed as particularly helpful in urban contexts and for transporting items.

A differentiated analysis points out the fact that, for all trip purposes, male respondents have statistically significantly higher rates of agreement for Vehicle on Demand. This is also the case for work and long-distance trips using Interstate Pilot. We also see that education levels, as measured by university-entrance diploma, have a significant impact on attitudes to Vehicle on Demand for long-distance (cross-country) trips, excursions and escorting trips. The presence of children in the household has a significantly positive impact on how useful Full Automation is viewed for trips in the city as well as cross-country. No correlation was seen for escorting trips, however. On long-distance and

Table 12.2 Respondents' stated answers to the question: "On which trips would you find such a vehicle to be particularly helpful?"

\begin{tabular}{|c|c|c|c|c|}
\hline & $\begin{array}{l}\text { Interstate } \\
\text { pilot }\end{array}$ & $\begin{array}{l}\text { Valet } \\
\text { parking }\end{array}$ & $\begin{array}{l}\text { Full } \\
\text { automation }\end{array}$ & $\begin{array}{l}\text { Vehicle on } \\
\text { demand }\end{array}$ \\
\hline$\ldots$ when I drive to work or college & -1.0 & -0.4 & -0.2 & -0.6 \\
\hline $\begin{array}{l}\text {.. when I go shopping or run } \\
\text { errands }\end{array}$ & -1.2 & 0.2 & -0.3 & -0.4 \\
\hline $\begin{array}{l}\ldots \text { which I pick people up or drop } \\
\text { them off }\end{array}$ & -0.8 & -0.4 & -0.1 & -0.5 \\
\hline $\begin{array}{l}\ldots \text { when I go somewhere for } \\
\text { recreational activities }\end{array}$ & -0.8 & -0.4 & -0.4 & -0.7 \\
\hline$\ldots$ when I travel or go on excursions & 0.1 & -0.1 & 0.4 & -0.2 \\
\hline $\begin{array}{l}\ldots \text { when I'm on the road for a long } \\
\text { time }\end{array}$ & 0.4 & -0.2 & 0.8 & 0.2 \\
\hline ... when I am in company & -0.4 & -0.4 & 0.0 & -0.4 \\
\hline$\ldots$ when I drive in the city & -1.1 & 0.5 & -0.1 & -0.4 \\
\hline$\ldots$ when I drive cross-country & -0.4 & -1.0 & 0.3 & -0.3 \\
\hline$\ldots$ when I have luggage with me & -0.9 & 0.3 & -0.4 & -0.5 \\
\hline
\end{tabular}

Mean values of answer options: -2 much more rarely; -1 more rarely; 0 as often; 1 more often; 2 much more often 
urban trips, the answers given for Valet Parking differ depending on household size and the presence of children. Employment status ${ }^{2}$ almost exclusively determines differences in the answers for Valet Parking on long trips, journeys to work, and for leisure activities; the latter also being conditioned by income level.

\subsubsection{What Do We Do on the Road Today, and What Will We Do Tomorrow?}

The possibility of pursuing other activities during a journey is one of automated driving's main features from a usage point of view. At the same time, time costs are a main driver of transport mode choice in models. To conclude, we shall therefore cast our eyes on the survey results regarding previous and also, perhaps, future time use.

The respondents were first asked how they generally occupied themselves while travelling on (urban) public transport, on (long-distance) trains or in cars. By far the most mentioned activity on public transport was enjoying the landscape and the journey: $50 \%$ of respondents stated doing this frequently or always on public transport, $66 \%$ on trains. Conversation with a companion or other passengers is similarly popular (public transport: $42 \%$, trains: $49 \%$ ), followed by listening to music, reading or relaxing. Around 77 and $69 \%$ of respondents stated they never work on local or long-distance journeys respectively; just under 6 and $8 \%$ frequently or always. The answers on working while on the move differ for train travel to statistically significant degrees according to sex, income, level of education, household size, and the presence of children. For example, $74 \%$ of women and $63 \%$ of men stated they never work on trains. Compared to comparably lower income groups, the likelihood of frequently or always working on board a train doubles with a net household income of over 2600 euros to around $10 \%$.

The current main activity in cars is, naturally, concentrating on the drive and the route. Around $80 \%$ of respondents also frequently or always listen to music, around two thirds talk to their companions, and over half frequently or always enjoy the trip and landscape while on the road. Seven percent state they sometimes work in cars.

Of the benefits that respondents perceive automated driving as having in terms of alternative time use during a journey, the most mentioned are being able to have conversations and enjoy the landscape - the most popular current activities in cars. As an example, Fig. 12.2 shows the answers for fully automated vehicles. The low proportion of those who see a benefit in being able to work while on the move is notable; in the case of Interstate Pilot this is less than a quarter of respondents.

\footnotetext{
${ }^{2}$ Employment status is classed as either full- or part-time employment, or other occupation.
} 


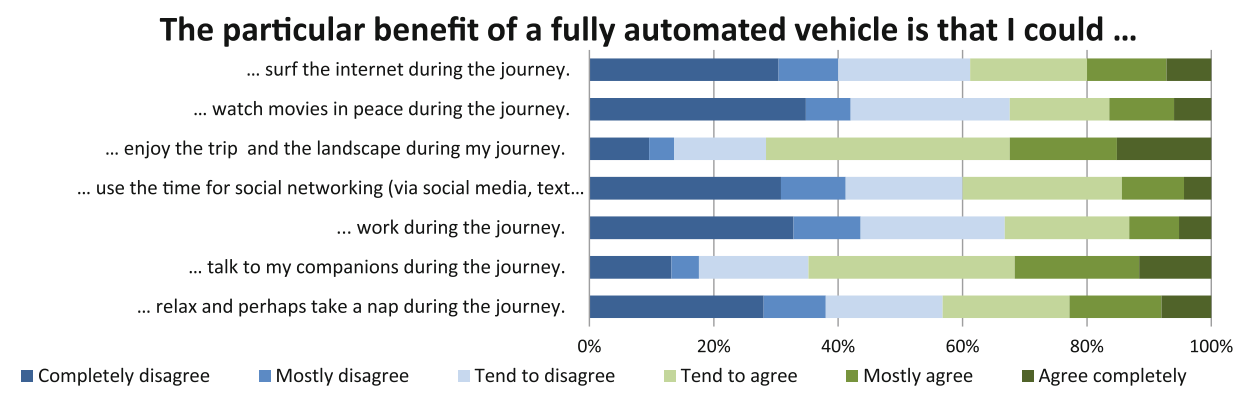

Fig. 12.2 Stated benefits of fully automated vehicles. Image rights: copyright by the Author

\subsection{Automated Vehicles in Demand Modeling: The Potential for, and Limits to, Their Integration}

Analyzing the possible effects of the various use cases clearly demonstrates the necessity of differentiation when integrating automated vehicles into demand modeling. While the Interstate Pilot and Valet Parking functions are both to a great extent particular, temporarily restricted special forms of an otherwise largely unchanged form of car driving and vehicle, the introduction of fully automated vehicles involves a practically new mode of transport or, in the case of a Vehicle on Demand fleet, potentially a completely new type of mobility provision.

Surely the greatest challenge in integrating automated driving into demand modeling lies in facilitating greater differentiation of the mode of passenger transport known as the "car." The conventional description of this transport mode option is based on the main criteria of travel time, running costs, and an often not further specified preference structure of the decision maker. Above all, this lacks the possibility of giving the role of the driver and the ownership status sufficient consideration. Differentiating between driving and being driven, and between driving one's own vehicle or any other one, is a prerequisite of adequate mapping. Only in this way is it possible to distinguish the role of the driver from that of the passenger or someone being chauffeured under Full Automation. Just as necessary is differentiation between conventional cars, fully automated vehicles, taxis, or hired Vehicles on Demand. The desire to integrate automated vehicles into the modeling therefore goes hand in hand with the need to describe the currently available individual alternatives with greater differentiation. The fluid transition between being a driver and a quasi-passenger, as experienced in the cases of Interstate Pilot and Full Automation, depending on the user and the journey, poses a particular challenge.

The time spent traveling is one of the most influential drivers of transport mode choice in current modeling. In modeling public transport, it is common to distinguish between on-board or actual travel time, waiting time, and time spent getting to and from the station or stop. This allows the time components to be evaluated differently. Until now, however, 
time spent in the vehicle has not been analyzed in any great depth, be it for public transport or any other mode. The expectations accompanying the introduction of automated vehicles, of being able to spend time in the vehicle in a subjectively more meaningful way, clearly indicate the necessity for differentiation in the models. Journey distance and duration, and thus also the potential usable proportion of the journey, merit greater attention here, as are the questions of which alternative activities are sought and with whom the journey is made.

But it is not only the time in the vehicle that is subject to change, there is also the most notable of the changes resulting from Valet Parking: minimizing the effort needed to use the mode at the beginning and end of the journey. The same applies for Vehicle on Demand. Again, we see here the necessity of further differentiating the often sweeping analysis of time spent traveling depending on the transport mode chosen. Concrete examples of this include the waiting time for a taxi and the time spent getting to one's own car, or a hired one.

One aspect that can be comparatively easily integrated into models, in simplified form, is the shortening of travel times resulting directly from the lack of traffic jams and traffic related to parking searches. More problematic is that the effect of increasingly reliable travel-time predictions on how cars are viewed as an alternative transport mode is usually unmapped in models. The increased convenience resulting from new functions such as Valet Parking or Interstate Pilot, the potential safety gains, and the greater flexibility of vehicle equipment are further examples of relevant subjective criteria that have barely been considered at all in model-based analyses up to now. The difficulty of recording subjective aspects, quantifying their effects, and taking them into consideration as factors in transport mode selection applies not only to a mode's properties, however, but also at least as much to describing the user. In particular, fun while driving, the perception of one's own driving skills, the readiness to hand over the driving function, the aversion to any potential loss of control, and trust in technology are all examples of factors that acquire greater relevance precisely in how automated vehicles are viewed (see Chap. 28). Such factors should thus be given greater attention in modeling.

Identifying user groups that differ in terms of how they assess the various transport mode options is one of the most important bases of describing people in models. Both the literature-based impact analysis and the survey results clearly indicate that automated vehicles' real or perceived benefits differ not only depending on the scenario, but also according to attitudes and socio-demographic characteristics. Besides the standard attributes of sex, employment status, age, and driver's license, further distinguishing factors that proved relevant included, depending on the usage scenario, presence of children in a household, level of education, and household income. In the course of representating automated vehicles, an expansion of the attributes used in models to describe people, and particularly their household context, consequently requires debate. Furthermore, it is also the case here that attitudinal factors, such as attitudes towards different transport modes, routines or temporal constraints, are hardly ever considered. 
For transport mode choice, holding a driver's license and access to a car are especially relevant individual and household attributes. The latter is generally expressed via the number of cars in a household or their actual availability on the behavioral survey's sample day. In macroscopic modeling, car availability is the standard criterion used to distinguish between user groups and determine trip rates. For transport mode selection itself, then, general car availability is presumed. Microscopic transport models permit consideration of driver's license possession as well as the actual car availability within the selection situation-whether constraints result from competition for a vehicle's use within the household or, especially, in the course of a trip chain. Systems such as Vehicle on Demand systematically break down this restriction to availability - this type of car can theoretically be selected as a new mobility option by anybody at any time. Just as with carsharing systems, adequate model representation requires a rethinking of, not least, the geographic and social criteria of car availability.

The consideration of geographic and contextual attributes, and the differentiation of possible usage or trip purposes, were given as further criteria for transport mode choice in models in Sect. 12.3.2. Particularly in the Valet Parking use case, the importance of geographic factors for how useful an option is perceived to be is intuitively apparent. Although the degree of detail in demand modeling is generally high enough to provide information about settlement structure, general land-use structure, and building density, details of building structure - crucial to whether there is sufficient public or even private parking - are not usually given. Detailed modeling of parking-space availability, pressure on parking space and the associated costs, and the time needed to get to and from parked cars are rarities (see Sect. 12.3.2). In this field, a general need for improvement can be stated if an adequate modeling of Valet Parking is to be achieved.

Vehicle on Demand is another example in which urban structure determines usage and the state of competition between existing transport modes to a considerable extent. It particularly forms an alternative to private cars, taxis, and public transport in urban areas, for example, whereas in rural areas it is mainly seen as a potential feeder service, and thus as a supplement to public transport. The job of modeling is therefore to anticipate worthwhile deployment concepts and availabilities, and to integrate these into the intermodal supply models. Further desirable improvements in transport supply models include the incorporation of parking-search traffic, and identifying route sections that are prime candidates for the use of automation.

The Vehicle on Demand use case makes it particularly clear what fundamental impact automated vehicles might have on our vehicle ownership, and thus on our everyday mobility decisions. The modeling and quantification of causal interrelationships - between ownership or other options for accessing a vehicle and its most important features, such as being equipped with Valet Parking or Full Automation on the one hand, and the supply-side, the geographic setting, and socio-demographic characteristics of the respective household on the other-take on increased significance here. The conventional approach of allowing solely for the ownership of an average car as an input parameter is being more and more superseded, especially for emissions calculations, by upstream models incorporating a household car's drive type, size class, price segment, number of 
seats, or cargo capacity. Support functions such as Valet Parking, however, play just as small a role in this as the alternative of carsharing membership or getting rid of a car due to good provision of alternative transport modes. It is not just the question of who could substitute owning a car with hiring one or being driven that remains unanswered in conventional means of modeling. Assuming that the combination of privately owned cars and various Vehicles on Demand particularly promotes the flexible adaptation of vehicle choice to the respective usage situation, then the necessity to gather and analyze the necessary data, and correspondingly expand the modeling becomes apparent.

\subsection{Summary and Outlook}

It is generally expected that automated vehicles in various forms will form part of our daily mobility in the near future. Integrating the relevant transport options into demand modelingone of the most important instruments in planning - is thus both equally challenging and necessary. Existing empirical work on the expected impact has until now focused primarily on the technology. At the same time, looking into the future is naturally full of uncertainty, and the effects of new technologies can only be appraised with difficulty.

If one looks at the individual use cases with regard to their potential impact on transport mode choice, then the need to distinguish between them is immediately apparent. Both Valet Parking and Interstate Pilot are mainly associated with lightly modified "normal" cars that offer a benefit in special situations: improved access to the vehicle and no need to search for a parking space in the case of Valet Parking, optional handing over of the driving function on selected routes or in special driving situations in the case of Interstate Pilot. The introduction of fully automated vehicles brings with it the idea of a substantial improvement in how time spent traveling in the vehicle is assessed, accompanied by fewer obstructions to car use. Far-reaching effects on the whole transport system can above all be seen in the scenario of broad availability of Vehicles on Demand, where individual mobility will be possible independently of driver proficiency or vehicle ownership. Presumably, this driverless urban carsharing will lead to a reduction in escorting trips and taxi use, as well as a clear drop in car ownership. In the countryside, it could open up access to public transport.

An online survey was employed to examine whether respondents could imagine using an automated vehicle in various usage scenarios and what transport modes they have been using until now these kinds of vehicles would substitute. Besides general skepticism, which even increased when the various scenarios were specified, the sizable influence of currently held attitudes towards cars is apparent. Sharp falls in taxi use are anticipated in particular. The specific advantages of automated vehicles are envisaged for long journeys especially, and also in the urban context in the case of Valet Parking. Taking pleasure in the journey and the landscape, and talking with fellow passengers are currently the preferred activities in both local and long-distance travel with public transport; more than two thirds of respondents state that they never work on the move. While travelling in cars, listening to music and conversation are among the most common activities. When asked 
about future time use when driving automated vehicles, enjoying the landscape and chatting are likewise the most prominent responses.

Not all factors relevant to how automated vehicles are perceived and evaluated can be incorporated into transport models, with their simplified representation of causal interrelationships in traffic generation. In particular, non-rational, "soft" perception and assessment factors, such as fun while driving, or the desire/reluctance to hand over the driving task, can only be empirically grasped and considered in models with difficulty. Both the empirical basis and the implementation in models show a need and potential for expansion here.

The main challenge in integrating automated vehicles, however, lies in what until now has only been a rudimentary differentiation of "cars" in models. Improvements in the empirical foundation, and the possibilities for integrating it into models, are again required here, including an underlining of the role of the driving task and vehicle ownership in transport mode choice. The aim is to allow for clearer distinctions between driving and being driven, between fully automated vehicles and ones which assist only when desired, and between privately owned cars, hired cars, and taxis. The need to rethink vehicle ownership as a fixed input variable is also apparent here.

The possibility of spending time on the move in different ways is, alongside safety, one of the most-mentioned benefits of the automation of driving. Time costs are also a key factor in modal choice in transport demand modeling. Until now, however, no differentiation of travel time has usually been provided for in models. It is not currently possible to distinguish between time spent in a "meaningful" way and time "wasted," between actively enjoying driving and being stuck in tiresome traffic jams, and between productive work and relaxed listening to music. Such an expansion of the models is not in principle difficult - initially independent of which alternative activity is actually being sought after. However, it is again evident that there are substantial gaps in the empirical foundation upon which demand modeling is built, that need filling before an adequate integration of automated driving can be achieved.

Open Access This chapter is distributed under the terms of the Creative Commons Attribution 4.0 International License (http://creativecommons.org/licenses/by/4.0/), which permits use, duplication, adaptation, distribution and reproduction in any medium or format, as long as you give appropriate credit to the original author(s) and the source, a link is provided to the Creative Commons license and any changes made are indicated.

The images or other third party material in this chapter are included in the work's Creative Commons license, unless indicated otherwise in the credit line; if such material is not included in the work's Creative Commons license and the respective action is not permitted by statutory regulation, users will need to obtain permission from the license holder to duplicate, adapt or reproduce the material.

\section{References}

1. Autoscout 24: Unser Auto von morgen: Studie zu den Wünschen der Europäer an das Auto von morgen. (2012).

2. Bamberg, S., Hunecke, M., Blöbaum, A.: Social context, personal norms and the use of public transportation: Two field studies. J. Environ. Psychol. 27, 190-203 (2007).

3. Becker, J.: Fahrplan in die Zukunft, Süddeutsche Zeitung, 18.1.2014, S.40. (2014). 
4. Bhat, C.R., Sardesai, R.: The impact of stop-making and travel time reliability on commute mode choice. Transp. Res. Part B Methodol. 40, 709-730 (2006).

5. Bates, J.J.: History of Demand Modelling. In: Hensher, D.A. and Button, K.J. (eds.) Handbook of Transport Modelling. pp. 11 - 34. Elsevier (2012).

6. Buehler, R.: Determinants of transport mode choice: a comparison of Germany and the USA. J. Transp. Geogr. 19, 644-657 (2011).

7. Castiglione, J., Bradley, M., Gliebe, J.: Activity-Based Travel Demand Models : A Primer. (2014).

8. Continental: Continental Mobilitätsstudie 2013. (2013).

9. Cervero, R., Kockelman, K.: Travel demand and the 3Ds: Density, diversity, and design. Transp. Res. Part D Transp. Environ. 2, 199-219 (1997).

10. Davidson, W., Donnelly, R., Vovsha, P., Freedman, J., Ruegg, S., Hicks, J., Castiglione, J., Picado, R.: Synthesis of first practices and operational research approaches in activity-based travel demand modeling. Transp. Res. Part A Policy Pract. 41, 464-488 (2007).

11. Fagnant, D.J., Kockelman, K.M.: Preparing a Nation for Autonomous Vehicles: Opportunities, Barriers and Policy Recommendations. Eno Cent. Transp. (2013).

12. Flade, A., Wullkopf, U.: Theorien und Modelle zur Verkehrsmittelwahl. Darmstadt (2002).

13. Giesel, F., Lenz, B.: Wirkung von E-Car-Sharing-Systemen auf Mobilität und Umwelt in urbanen Räumen, unveröffentlichte WiMobil-Projektpräsentation. (2014).

14. Giesel, F., Nobis, C., Lenz, B.: Carsharing as a Driver of Sustainable Urban Mobility? An Analysis of User Structure and Motivation, unveröffentlichte Präsentation auf der AAG Conference in Tampa, USA. (2014).

15. Glotz-Richter, M., Loose, W., Nobis, C.: Car-Sharing als Beitrag zur Lösung von städtischen Verkehrsproblemen. Int. Verkehrswes. 59, 333-337 (2007).

16. Kahneman, D., Krueger, A.B.: Development in the Measurement of Subjective Well-Being. J. Econ. Perspect. 20, 3-24 (2006).

17. KPMG: Self-Driving Cars: Are We Ready? (2013).

18. Kutter, E.: Modellierung für die Verkehrsplanung. Theoretische, empirische und planungspraktische Rahmenbedingungen. ECTL Working Paper 21, TU Hamburg-Harburg. (2003).

19. Litmann, T.: Ready or waiting? Traffic Technol. Int. 37-42 (2014).

20. Maier, G., Weiss, P.: Modelle diskreter Entscheidungen: Theorie und Anwendung in den Sozial- und Wirtschaftswissenschaften. Springer (1990).

21. Nally, M.G., Rindt, C.: The activity-based approach. In: Hensher, D.A. and Button, K. (eds.) Handbook of Transport Modelling. pp. 53-69. Elsevier (2012).

22. McNally, M.G.: The Four-Step Model. In: Hensher, D.A. and Button, K. (eds.) Handbook of Transport Modelling. pp. 35-54. Elsevier (2012).

23. Munsch, E.: Autonomes Fahren: Platz sparen mit dem Bordcomputer, http://www.zeit.de/ mobilitaet/2014-05/autonomes-fahren-feldversuch-schweden. (2014). Letzter Zugriff 28.6. 2014.

24. Ortùzar, J., Willumsen, L.G.: Modelling Transport, 3. Auflage. Wiley, Chichester (2005).

25. Ory, D.T., Mokhtarian, P.L.: When is getting there half the fun? Modeling the liking for travel. Transp. Res. Part A Policy Pract. 39, 97-123 (2005).

26. Rinspeed: Rinspeed - Creative think tank for the automotive industry. Where the future is reality - today. http://www.rinspeed.eu/aktuelles.php?aid=15. (2014). Letzter Zugriff 28.6. 2014.

27. Scheiner, J., Holz-Rau, C.: Travel mode choice: affected by objective or subjective determinants? Transportation (Amst). 34, 487-511 (2007). 
28. Scheiner, J., Holz-Rau, C.: Gendered travel mode choice: a focus on car deficient households. J. Transp. Geogr. 24, 250-261 (2012).

29. Schwanen, T., Banister, D., Anable, J.: Rethinking habits and their role in behaviour change: the case of low-carbon mobility. J. Transp. Geogr. 24, 522-532 (2012).

30. Silberg, G., Wallace, R., Matuszak, G.: Self-driving cars: The next revolution. KPMG and Center for Automotive Research. (2012).

31. Simma, A., Axhausen, K.W.: Commitments and Modal Usage: Analysis of German and Dutch Panels. Transp. Res. Rec. J. Transp. Res. Board. 1854, 22-31 (2003).

32. Sokolow, A.: Autonome Autos: Autobranche vs. Google, http://m.heise.de/newsticker/ meldung/Autonome-Autos-Autobranche-vs-Google-2072050.html. (2013). Letzter Zugriff 28.6.2014.

33. Steg, L.: Car use: lust and must. Instrumental, symbolic and affective motives for car use. Transp. Res. Part A Policy Pract. 39, 147-162 (2005).

34. Train, K.E.: A comparison of the predictive ability of mode choice models with various levels of complexity. Transp. Res. Part A Gen. 13, 11-16 (1979).

35. Walker, J.L.: Beyond Rationality in Travel Demand Models. ACCESS Mag. 1, https:// escholarship.org/uc/item/1x04f3k3. (2011). Letzter Zugriff 28.6.2014.s

36. Wardman, M.: Public transport values of time. Transp. Policy. 11, 363-377 (2004).

37. Willumsen, L.G.: Forecasting the impact of Self-Driving-Cars. What to do about them in our models and forecasts. Vortrag auf der 2013 Citilab Asia User Conference, Karon, Thailand, unveröffentlicht. (2013). 